\title{
Comparison of dynamic hip screw and antirotation screw with cannulated screw in the treatment of transcervical collum femoris fractures
}

\author{
Adem Şahin, MD(D, Anıl Agar, MD (D), Deniz Gülabi, MD(D), Cemil Ertürk, MD®D \\ Department of Orthopedics and Traumatology, University of Health Sciences, \\ Kanuni Sultan Süleyman Training and Research Hospital, Istanbul, Turkey
}

Femoral neck fractures in young patients are mostly seen after high-energy trauma. Internal fixation methods are the gold treatment choice in young, healthy, and active patients with good bone quality. ${ }^{[1]}$

Potential complications after trauma and surgery make the treatment of these fractures more challenging. Various surgical methods and fixation options have been proposed for the surgical treatment of femoral neck fractures. ${ }^{[2]}$ Anatomic reduction is the most important factor in internal fixation of femoral neck fractures. The time to surgery (from trauma to operating theatre), capsulotomy, and the implant choices are controversial in the literature. ${ }^{[3]}$ Many types of implants are used for internal fixation of femoral neck fractures. ${ }^{[3]}$ Osteosynthesis with cannulated screws (CSs) and dynamic hip screws (DHSs) are the most commonly used modalities. ${ }^{[4]}$ Although internal fixation of femoral neck fractures provides blood flow to the femoral neck, complications such as non-union and avascular necrosis (AVN) are still seen in 10-20\% and $10-30 \%$ of cases, respectively. ${ }^{[5,6]}$ In addition, joint replacement is performed in $20-36 \%$ of these

Received: January 09, 2020

Accepted: March 24, 2020

Published online: June 18, 2020

Correspondence: Anıl Agar, MD. Kanuni Sultan Süleyman Eğitim ve Araştırma Hastanesi Ortopedi ve Travmatoloji Kliniği, 34303 Küçükçekmece, İstanbul, Türkiye.

E-mail: dr.anilagar@hotmail.com

Doi: $10.5606 /$ ehc. 2020.73416

Citation: Şahin A, Agar A, Gülabi D, Ertürk C. Comparison of dynamic hip screw and antirotation screw with cannulated screw in the treatment of transcervical collum femoris fractures. Jt Dis Relat Surg 2020;31(2):320-327.

\section{ABSTRACT}

Objectives: This study aims to compare the results of internal fixation with dynamic hip screw (DHS)/antirotation screw and conventional cannulated screw (CS) for femoral neck fracture.

Patients and methods: This retrospective study included a total of 78 patients (57 males, 21 females) with collum femoris fractures treated with internal fixation between January 2015 and January 2019. Group 1 comprised 41 patients with a mean age of 45.7 years (range, 19 to 62 years) treated with DHSs/antirotation screws, while group 2 comprised 37 patients with a mean age of 41.9 years (range, 17 to 75 years) treated with CSs. The patients were evaluated for union, avascular necrosis (AVN), femoral neck shortness, operation time, duration of fluoroscopy exposure, and functional outcomes.

Results: Age, gender, and Garden classification stages were similar in both groups. No significant difference was found between the groups in respect of $\mathrm{AVN}$ and non-union rates. The non-union rate was $12.2 \%$ in group 1 and $21.6 \%$ in group 2 ( $>>0.05)$. The duration of fluoroscopy exposure was statistically significantly higher in group $2(\mathrm{p}=0.001)$ and the operation time was statistically significantly longer in group $1(\mathrm{p}=0.001)$. In group 2 , femoral neck shortness stature was significantly higher $(\mathrm{p}=0.007)$. At the final follow-up examination, the Harris hip score was statistically significantly higher in group $1(\mathrm{p}=0.04)$.

Conclusion: Dynamic hip screw/antirotation screw was a more relevant treatment method for transcervical femoral neck fractures compared to CS with more favorable functional outcomes and less fluoroscopy exposure.

Keywords: Femoral neck fracture, femur head necrosis, fluoroscopy, fractures, internal fixators, non-union, operation time.

cases who develop degenerative arthritis due to non-union and AVN. ${ }^{[7,8]}$

Cannulated screw application has many advantages, such as superior torsional stability, limited vascular damage and minimally invasive application, less soft tissue damage, reduced blood loss, and patient satisfaction. It is also thought to reduce the rate of AVN development as it causes less damage to 
the cancellous bone. However, CSs have low resistance to bending and shearing forces. ${ }^{[1]}$ Dynamic hip screws are twice as resistant to physiological loads than CSs. Therefore, with superior biomechanical properties and excellent fracture stability, it is thought that DHSs may reduce the need for revision surgery. Disadvantages such as a longer operation time and greater blood loss compared to CSs are reduced with minimal incisions. ${ }^{[1,9]}$ In biomechanical studies, particularly in vertical fractures caused by high-energy trauma, DHS fixation is better than multiple CSs. ${ }^{[10,11]}$ Majernicek reported that the DHS method is an economic, appropriate, and therapeutic approach that provides adequate results compared to other findings in the literature. ${ }^{[12]}$ Although DHS has traditionally been used in extracapsular femoral fractures, it can also be used in rotationally unstable intracapsular femoral neck fractures when applied with an antirotation screw. ${ }^{[13,14]}$ Theoretically, the antirotation screw provides axial stability, and therefore controls distal translation of the proximal fragment. ${ }^{[15]}$

Our hypothesis was that favorable functional outcomes with less radiation exposure could be gained with the DHS fixation technique. Therefore, in this study, we aimed to compare the results of internal fixation with DHS/antirotation screw and conventional CS for femoral neck fracture.

\section{PATIENTS AND METHODS}

For this retrospective study, medical records were reviewed of patients treated for the diagnosis of collum femoris fracture at University of Health Sciences, Kanuni Sultan Süleyman Training and Research Hospital between January 2015 and January 2019. From 128 patients identified, 50 were excluded because of subcapital or basocervical fracture $(n=40)$, or because of previous hip surgery $(n=10)$. The study group was limited to 78 patients $(57$ males, 21 females). These 78 patients returned for a follow-up investigation. Group 1 comprised 41 patients (mean age 45.7 years; range, 19 to 62 years) treated with DHS/antirotation screw, while group 2 comprised 37 patients (mean age 41.9 years; range, 17 to 75 years) treated with CS. The inclusion criteria of the study were age between 17 and 75 years, a diagnosis of transcervical fracture only, and the completion of an adequate follow-up period. Patients were excluded if they had a subcapital or basocervical collum femoris fracture, multiple trauma with head and/or chest trauma, any additional fracture of the same lower extremity, previous surgery of the involved extremity, any rheumatic disease, chronic systemic disease, malignancy, or if they underwent open hip reduction.
A database was established including patients' demographic data, fracture type according to the Garden classification, operation time, type of implant, interval from trauma to surgery, hospital stay, and data from clinical and radiographic follow-up. All procedures followed were in accordance with the ethical standards of the responsible committee on human experimentation (institutional and national) and with the Helsinki Declaration of 1975, as revised in 2008. Informed consent was obtained from all patients for being included in the study).

The Garden classification was used to determine the fracture type preoperatively. All patients were checked radiologically at follow-up visits. ${ }^{[16]}$ True pelvis anteroposterior (AP) and AP and lateral radiographs of the involved hips were taken to check the union and shortness of the femoral neck. The images were evaluated and all radiological assessments were taken by a single radiologist who was well experienced in the skeletal system and blinded to the study. The independent observer assessed all radiographs twice at an interval of one week. The mean of the two measurements was used to calculate the differences between the groups.

All patients were operated on by the orthopedic teams as soon as possible after hospitalization. The surgical team performed the surgery under the supervision of the senior surgeon. All patients received intravenous cefazolin sodium ( $1 \mathrm{~g})$ before the operation and this was continued for 24 hours postoperatively. To prevent deep vein thrombosis, low molecular weight heparin was started preoperatively and was administered for three weeks postoperatively. Under general or regional anesthesia, closed hip reduction was applied to all patients on a traction table under the C-arm. In group 1, lateral exposure was obtained through the tensor fascia lata. A DHS (a 135', three-hole plate branded TST; TST Tibbi Aletler San. ve Tic. Ltd. Sti., Istanbul, Turkey) was applied as described in the original technique ${ }^{[14]}$ after reduction under C-arm without opening the capsule. Then, one $6.5 \mathrm{~mm}$ CS was used for antirotation to $1.5 \mathrm{~cm}$ above the DHS screw (Figure 1) ${ }^{[17]}$ The reduction was compared with the contralateral hip; $10^{\circ}$ varus and $15^{\circ}$ valgus were evaluated as sufficient. In group 2, after closed reduction under the C-arm, 6.5 CSs were applied first to the inferior part of the femoral neck, then near to the posterior cortex, and finally one more screw was applied to the anterior side of the femoral neck to complete the inverted triangular configuration without using any extramedullary guide (Figure 2). Operation times and duration of fluoroscopy usage in all patients were recorded. 
All patients started isometric and isokinetic exercises on the first postoperative day and were mobilized without weight bearing. Patients were called for physical examination and radiological follow-up at 1, 3, 6 and 12 months postoperatively. In both groups, patients were ambulated with crutches and toe-touch weight bearing for six weeks. When follow-up radiographs showed sufficient healing and a pain-free hip was achieved clinically, patients were permitted full weight bearing, using crutches for three months.

Avascular necrosis was evaluated according to the Ficat criteria. ${ }^{[18]}$ The radiological assessment of the operated hip was performed with AP and lateral radiographs of the hip during postoperative follow-up examinations. The absence of bridging of the fracture line and progressive displacement at six months postoperatively were considered as non-union and all patients with non-union were referred for a second surgery of total hip arthroplasty. Measurements were taken of the length of the femoral neck in the axis of the center-collum-diaphysis angle, and the distance between the center of the femoral head and the caudal end of the lesser trochanter (to evaluate femoral shortening) on both sides. Pelvis AP radiographs were used to assess the femoral neck shortness.

The Harris hip evaluation score was used to evaluate the functional results of the patients. In this scoring, the degree of pain, daily activities, and range of motion are evaluated. ${ }^{[19]}$ At the final follow-up examination, the Harris hip scores were assessed by an independent assessor. The assessor was blinded to
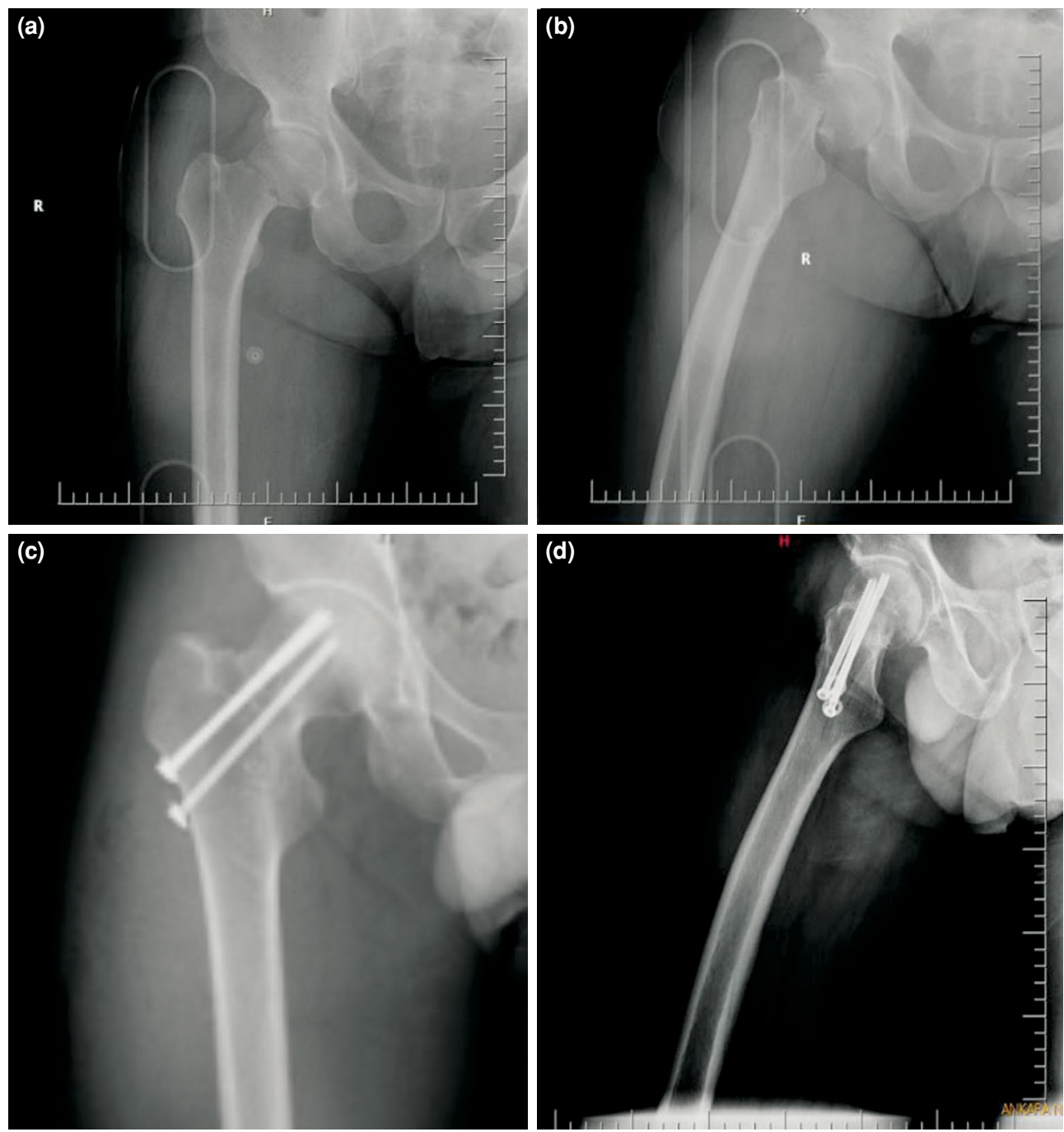

FIGURE 1. A 56-year-old male patient, right hip, operated at 22 hours after trauma. (a) Preoperative anteroposterior graphy. (b) Preoperative lateral graphy. (c) Postoperative anteroposterior graphy at six months. (d) Postoperative lateral graphy at six months. 

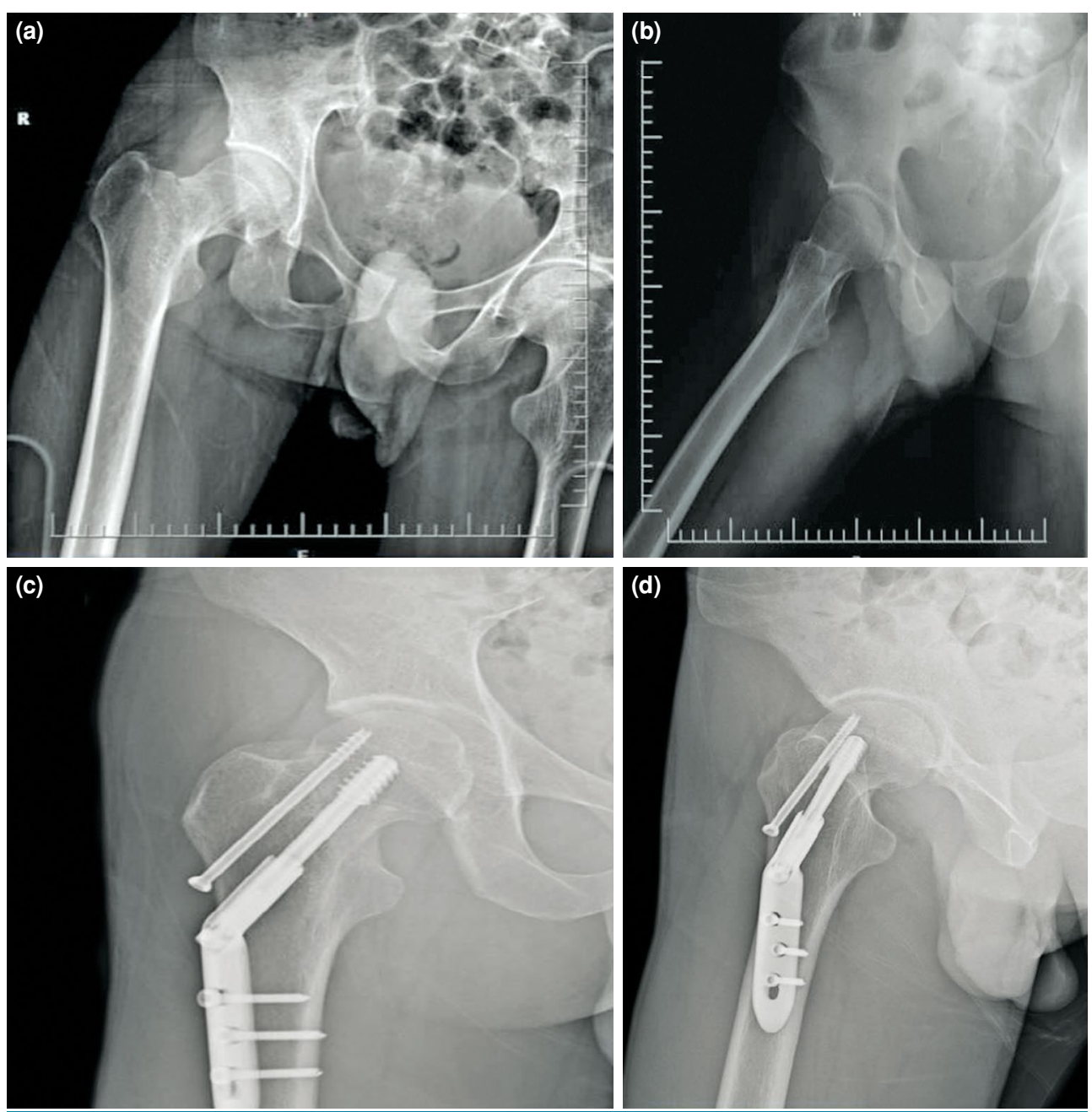

FIGURE 2. A 49-year-old male patient, right hip, operated at 14 hours after trauma. (a) Preoperative anteroposterior graphy. (b) Preoperative lateral graphy. (c) Postoperative anteroposterior graphy at six months. (d) Postoperative lateral graphy at six months.

the surgical technique and performed all assessments twice in one day. The mean value of each score was used for the statistical analysis.

\section{Statistical analysis}

Data obtained in the study were analyzed statistically using IBM SPSS Statistics version 22.0 software (IBM Corp., Armonk, NY, USA). In the evaluation of the study data, in addition to descriptive statistical methods (mean, standard deviation), the Student's t-test was used to compare quantitative parameters with normal distribution between the two groups, and the Mann-Whitney U test was applied to comparisons between the groups of parameters not showing normal distribution. In the comparison of qualitative data, the chi-square test and Yates' correction for continuity test were used. A $p$ value $<0.05$ was accepted as statistically significant.

\section{RESULTS}

The mean follow-up period was 18.1 months (range, 12 to 36 months) for group 1 and 14.2 months (range, 12 to 25 months) for group 2. According to the Garden classification for fracture classification, type I fracture was determined in two patients, type II fracture in 42 patients, type III fracture in 27 patients, and type IV fracture in seven patients (Table I). The demographic data of the groups are shown in Table I. The mechanism of trauma was 31 falls, eight traffic accidents, and two assaults in group 1, and 28 falls, eight traffic accidents, and one gunshot injury in group 2 . The time from trauma to 


\begin{tabular}{|c|c|c|c|c|c|c|c|}
\hline & $\mathrm{De}$ & raphic & $\begin{array}{l}\text { BLE I } \\
\text { stribution of }\end{array}$ & tient & & & \\
\hline & & amic & screw & & nnulate & screw & \\
\hline & $n$ & $\%$ & Mean $\pm S D$ & $\mathrm{n}$ & $\%$ & Mean $\pm S D$ & $p$ \\
\hline Age (year) & & & $45.7 \pm 12.6$ & & & $41.9 \pm 13.9$ & $0.211^{*}$ \\
\hline Gender & & & & & & & $0.984 \dagger$ \\
\hline Male & 30 & 73.2 & & 27 & 73 & & \\
\hline Female & 11 & 26.8 & & 10 & 27 & & \\
\hline Side & & & & & & & $0.068+$ \\
\hline Right & 17 & 41.5 & & 23 & 62.2 & & \\
\hline Left & 24 & 58.5 & & 14 & 37.8 & & \\
\hline Additional fracture & 8 & 19.5 & & 3 & 8.1 & & $0.263 \ddagger$ \\
\hline Comorbid diseases & 11 & 26.8 & & 9 & 24.3 & & $1.000 \ddagger$ \\
\hline
\end{tabular}

operation was mean 10.1 hours (range, 4 to 36 hours) in group 1 and 12 hours (range, 5 to 48 hours) in group 2. The length of hospital stay was 2.9 days (range, 2 to 6 days) in group 1 and 2.3 days (range, 1 to 5 days) in group 2 (Table II).

The mean duration of fluoroscopy use was 49.8 seconds (range, 22 to 75 seconds) in group 1 and 70.3 seconds (range, 45 to 95 seconds) in group 2. The mean operation time in group 1 was 73.1 minutes (range, 60 to 100 minutes) and 50 minutes (range, 40 to 90 minutes) in group 2 (Table II).
Femoral neck shortening was $6.6 \mathrm{~mm}$ (range, 2 to $20 \mathrm{~mm}$ ) in group 1 and $9.5 \mathrm{~mm}$ (range, 2 to $28 \mathrm{~mm}$ ) in group 2. At the final follow-up visit, the Harris hip score was 78.9 (range, 19 to 100) in group 1 and 68.3 (range, 15 to 95) in group 2 (Table II).

Two patients in group 1 had superficial wound infection and were treated with local wound care. Screw revision was performed in one patient in group 1 due to screw migration from the femoral head to the acetabulum. Pulmonary embolism developed in one patient, who was then referred to

\begin{tabular}{|c|c|c|c|c|c|c|c|c|c|}
\hline \multicolumn{10}{|c|}{$\begin{array}{l}\text { TABLE II } \\
\text { valuation of operation proper }\end{array}$} \\
\hline & \multicolumn{4}{|c|}{ Dynamic hip screw } & \multicolumn{4}{|c|}{ Cannulated screw } & \multirow[b]{2}{*}{$p$} \\
\hline & $\mathrm{n}$ & $\%$ & Mean $\pm S D$ & Median & $\mathrm{n}$ & $\%$ & Mean $\pm S D$ & Median & \\
\hline Time from trauma to operation (hours) & & & $10.1 \pm 6.5$ & 7 & & & $12 \pm 9.7$ & 8 & $0.397 \dagger$ \\
\hline Follow-up time (months) & & & $18.1 \pm 6.6$ & 18 & & & $14.2 \pm 5.35$ & 14 & $0.010^{*} \dagger$ \\
\hline Operation time (minutes) & & & $73.1 \pm 12.1$ & 73.1 & & & $50 \pm 12.3$ & 45 & $0.001^{* *} \dagger$ \\
\hline Duration of fluoroscopy (seconds) & & & $49.8 \pm 10.4$ & 50 & & & $70.3 \pm 11.9$ & 70 & $0.001^{* *} \dagger$ \\
\hline Hospitalization length (days) & & & $2.9 \pm 1.4$ & 2 & & & $2.3 \pm 0.8$ & 2 & $0.022^{*} \dagger$ \\
\hline Femoral neck shortness (mm) & & & $6.6 \pm 4.2$ & 5 & & & $9.5 \pm 5.9$ & 8 & $0.007^{* *} \dagger$ \\
\hline ASA score & & & $1.2 \pm 0.5$ & 1 & & & $1.5 \pm 0.7$ & 1 & $0.160 \dagger$ \\
\hline Harris Hip score & & & $78.9 \pm 21.3$ & & & & $68.3 \pm 25$ & & $0.047^{\star} \ddagger$ \\
\hline Garden classification & & & & & & & & & $0.016^{*} \S$ \\
\hline Type I & 0 & 0 & & & 2 & 5.4 & & & \\
\hline Type II & 28 & 68.3 & & & 14 & 37.8 & & & \\
\hline Type III & 12 & 29.3 & & & 15 & 40.5 & & & \\
\hline Type IV & 1 & 2.4 & & & 6 & 16.2 & & & \\
\hline Non-union & 5 & 12.2 & & & 8 & 16.2 & & & 0.4179 \\
\hline
\end{tabular}




\begin{tabular}{|ccc|}
\multicolumn{4}{c|}{ TABLE III } \\
Avascular necrosis distribution of study groups \\
\hline Ficat classification & Group 1 $(\mathrm{n}=41)$ & Group $2(\mathrm{n}=37)$ \\
\hline 0 & 16 & 12 \\
1 & 17 & 17 \\
2 & 3 & 4 \\
3 & 4 & 4 \\
4 & 1 & 0 \\
\hline
\end{tabular}

the Pulmonology Clinic and underwent antiembolic treatment. No infection was observed in the followup of group 2. Two patients underwent screw revision due to screw migration.

Femoral neck AVN was evaluated at the final follow-up examination according to the Ficat classification. Stage 0 AVN was determined in 28 patients, stage I in 34, stage II in seven, stage III in eight patients, and stage IV in one patient (Table III). Patients with stage III AVN, had minimal symptoms and decompression surgery to the femoral neck was recommended, but the patients refused. Total hip replacement surgery was performed on the patient with Ficat stage IV AVN.

Non-union was determined in 13 patients during the follow-up period ( $n=5$ in group 1 and $n=8$ in group 2). One patient with non-union was addicted to narcotic drugs and refused further treatment in group 1, while the other 12 patients were applied total hip replacement in both groups.

\section{DISCUSSION}

Internal fixation with CS or DHS is used in the treatment of femoral neck fractures. ${ }^{[17]}$ Particularly in displaced femoral neck fractures, the treatment is surgical while the main question is the type of technique to be applied. The use of hip arthroplasty or internal fixation may depend on patient age, the presence of other systemic diseases, mental status, social activity level, and the time from trauma to diagnosis of the fracture. ${ }^{[20]}$ Internal fixation is currently more widely used than arthroplasty because of the low cost and treatment of patient's own bone. ${ }^{[21]}$

The findings of this study indicate that DHS/ antirotation screw is a more relevant treatment method for femoral neck fractures compared to CS, with more favorable functional outcomes and less fluoroscopy exposure. ${ }^{[22]}$

In the present study, the non-union rates were evaluated as $12 \%$ in group 1 and $21 \%$ in group 2. Although the rate of non-union was higher in group 2, there was no statistically significant difference between the two groups $(p=0.41)$ while proportionally more non-union was observed in group 2. The non-union rates in both groups were in accordance with the literature. Levi ${ }^{[23]}$ compared the failure rates of 456 patients with DHSs and three CSs for transcervical fractures and reported that the results of both surgical techniques were similar. In a meta-analysis of 25 randomized controlled clinical trials involving 4,925 patients with intracapsular femoral neck fractures treated with various implants, Parker and Blundell[24] reported that none of the implants were superior to others in terms of nonunion or fracture displacement. However, in a series of 58 cases, Siavashi et al. ${ }^{[17]}$ argued that DHS was a better fixation method as non-union was seen in five patients who were applied CS, while no complications were observed in the DHS patients.

The time from trauma to surgery is another controversial issue that has been focused on in previous studies. Swiontkowski ${ }^{[14]}$ reported that in young patients, morbidity can be significantly reduced with immediate reduction and internal fixation following a femoral neck fracture. In a retrospective study of 38 patients, Jain et al. ${ }^{[25]}$ compared early ( $<12$ hours) and delayed ( $>12$ hours) operation times. Osteonecrosis was reported to have developed in $16 \%$ of the patients and all of them were in the delayed group. It was concluded that late surgery increased the rate of osteonecrosis, but did not affect functional outcomes. ${ }^{[25]}$ In contrast, Haidukewych et al. ${ }^{[6]}$ reported that AVN developed in $25 \%$ of patients operated on within 24 hours and in $20 \%$ of patients operated on after 24 hours. Upadhyay et al. ${ }^{[26]}$ showed that there was no difference in AVN development and non-union rates between patients who underwent surgery within 48 hours of the trauma and those for whom surgery was started after 48 hours. Most studies have suggested that surgery should be performed within the first 24-48 hours to be able to preserve the feeding of the femoral head. In the current study, the mean time from trauma to surgery was 11 hours (range, 4 to 36 hours) in the DHS group and 12 hours (range, 5 to 48 hours) in the CS group. There was no difference between the two groups in terms of operation timing $(\mathrm{p}=0.39)$. The results of this study suggest that there is no relationship between the duration of time to surgery and non-union and the development of complications such as AVN. Similarly, the time to surgery did not affect functional outcomes.

The duration of fluoroscopy time in group 1 was significantly lower than in group 2 . The mean 
fluoroscopy time was 49 seconds in group 1 and 70 seconds in group $2(p=0.001)$. The reason for this can be considered to be due to the use of an extramedullary guide with DHS fixation and the desired screw position being achieved with less fluoroscopy usage as the guidewire is more rigid. In addition, the guidewire can be inserted into the DHS and advanced in parallel with the antirotation screw. The problem faced in group 2 was the difficulty in obtaining the desired screw configuration while placing the screws. This is because the free-hand technique was used for the screwing, and the guide Kirschner wires passing through the screw were thin, making it difficult to screw in the desired direction. Therefore, fluoroscopy is required more to achieve the correct screw configuration.

In the present study, the operation time was 73.1 minutes for group 1 and 51.7 minutes for group 2, with the difference determined as statistically significant $(p=0.001)$. In a study by Singh et al., ${ }^{[27]}$ the operation time was found to be shorter in the CS group compared to patients who underwent DHS (55.6 minutes in the cannulated group vs. 86 minutes in the DHS group). In another study by Kaplan et al., ${ }^{[21]}$ a significant difference was found between the operation times of the groups: 46 minutes (range, 15 to 60 minutes) in the CS group and 95 minutes (range, 50 to 240 minutes) in the DHS group. In the present study, the mean operation time in group 1 of 51.7 minutes was significantly shorter than the 73.1 minutes of group 2 . This can be considered to be due to the lack of external guides for the CS fixation technique and shorter fluoroscopy usage.

Femoral neck shortness after internal fixation of the femoral neck fracture is a common complication with reported rates of approximately $31 \%{ }^{[28]}$ It has been reported that even a $5 \mathrm{~mm}$ shortening may affect hip functions resulting in limping. ${ }^{[28]}$ According to Mattsson, ${ }^{[29]}$ if the shortness of the femoral neck is less than $6.7 \mathrm{~mm}$, it does not affect hip function. In the present study, femoral neck shortness was found to be significantly higher in the CS group $(\mathrm{p}=0.007)$. Mean femoral neck shortening was measured as $9.5 \mathrm{~mm}$ (range, 2 to $28 \mathrm{~mm}$ ) in group 2 and $6.5 \mathrm{~mm}$ (range, 2 to $20 \mathrm{~mm}$ ) in group 1 . In a study by Sivashi, ${ }^{[17]}$ femoral neck shortening was found to be $1.5 \mathrm{~cm}$ (range, 0 to $2.5 \mathrm{~cm}$ ) in the CS group and $1 \mathrm{~cm}$ (range, 0 to $1.1 \mathrm{~cm}$ ) in the DHS group.

Harris hip scoring is a classification that evaluates pain and daily living activities of patients. In the present study, the mean Harris hip score was 78 in group 1 and 68 in group 2. The functional results were significantly better in group 1 patients $(p=0.04)$.
In a study by Kaplan et al., ${ }^{[21]}$ the mean hip score was reported to be 91 (range, 65 to 100) in patients applied CSs and 80 (range, 75 to 99) in those with DHS, with no statistically significant difference between the groups. In contrast, Sivashi ${ }^{[17]}$ reported a mean Harris hip score of 83 (range, 60 to 100) in the CS group and 92 (range, 65 to 100) in the DHS group. In the current study, the Harris hip score was found to be lower in group 2 because femoral neck shortness was higher.

There were some limitations of this study, including primarily the retrospective design and the comparatively low number of patients who met the inclusion criteria. Nevertheless, 78 patients returned as invited for a final follow-up examination. Despite these limitations, this study successfully demonstrated a comparison of DHSs/antirotation screws and CSs.

In conclusion, the findings of this study indicate that DHS/antirotation screw is a more relevant treatment method for femoral neck fractures compared to CS, with more favorable functional outcomes and less fluoroscopy exposure.

\section{Declaration of conflicting interests}

The authors declared no conflicts of interest with respect to the authorship and/or publication of this article.

\section{Funding}

The authors received no financial support for the research and/or authorship of this article.

\section{REFERENCES}

1. Bhandari M, Tornetta P 3rd, Hanson B, Swiontkowski MF. Optimal internal fixation for femoral neck fractures: multiple screws or sliding hip screws? J Orthop Trauma 2009;23:403-7.

2. Shah AK, Eissler J, Radomisli T. Algorithms for the treatment of femoral neck fractures. Clin Orthop Relat Res 2002;399:28-34.

3. Miyamoto RG, Kaplan KM, Levine BR, Egol KA, Zuckerman JD. Surgical management of hip fractures: an evidencebased review of the literature. I: femoral neck fractures. J Am Acad Orthop Surg 2008;16:596-607.

4. Gem M, Özkul E, Alemdar C, Kapukaya A, Arslan H, Atiç R. Comparison of cannulated screw and dynamic hip screw for the treatment of femoral neck fractures. JCEI 2015;6:256-62.

5. Angelini M, McKee MD, Waddell JP, Haidukewych G, Schemitsch EH. Salvage of failed hip fracture fixation. J Orthop Trauma 2009;23:471-8.

6. Haidukewych GJ, Rothwell WS, Jacofsky DJ, Torchia ME, Berry DJ. Operative treatment of femoral neck fractures in patients between the ages of fifteen and fifty years. J Bone Joint Surg [Am] 2004;86:1711-6.

7. Bosch U, Schreiber T, Krettek C. Reduction and fixation of displaced intracapsular fractures of the proximal femur. Clin Orthop Relat Res 2002;399:59-71. 
8. Kold S, Bechtold JE, Mouzin O, Elmengaard B, Chen X, Søballe K. Fixation of revision implants is improved by a surgical technique to crack the sclerotic bone rim. Clin Orthop Relat Res 2005;432:160-6.

9. Lee YS, Chen SH, Tsuang YH, Huang HL, Lo TY, Huang CR. Internal fixation of undisplaced femoral neck fractures in the elderly: a retrospective comparison of fixation methods. J Trauma 2008;64:155-62.

10. Aminian A, Gao F, Fedoriw WW, Zhang LQ, Kalainov DM, Merk BR. Vertically oriented femoral neck fractures: mechanical analysis of four fixation techniques. J Orthop Trauma 2007;21:544-8.

11. Baitner AC, Maurer SG, Hickey DG, Jazrawi LM, Kummer FJ, Jamal J, et al. Vertical shear fractures of the femoral neck. A biomechanical study. Clin Orthop Relat Res 1999;367:300-5.

12. Majernícek M, Dungl P, Kolman J, Malkus T, Vaculík J. Osteosynthesis of intracapsular femoral neck fractures by dynamic hip screw (DHS) fixation. Acta Chir Orthop Traumatol Cech 2009;76:319-25.

13. Ly TV, Swiontkowski MF. Management of femoral neck fractures in young adults. Indian J Orthop 2008;42:3-12.

14. Swiontkowski MF. Intracapsular fractures of the hip. J Bone Joint Surg [Am] 1994;76:129-38.

15. Massoud EI. Fixation of basicervical and related fractures. Int Orthop 2010;34:577-82.

16. Garden RS. Low-angle fixation in fractures of the femoral neck. J Bone Joint Surg [Br] 1961;43:647-63.

17. Siavashi B, Aalirezaei A, Moosavi M, Golbakhsh MR, Savadkoohi D, Zehtab MJ. A comparative study between multiple cannulated screws and dynamic hip screw for fixation of femoral neck fracture in adults. Int Orthop 2015;39:2069-71.

18. Ficat RP. Idiopathic bone necrosis of the femoral head. Early diagnosis and treatment. J Bone Joint Surg [Br] 1985;67:3-9.

19. Harris WH. Traumatic arthritis of the hip after dislocation and acetabular fractures: treatment by mold arthroplasty. An end-result study using a new method of result evaluation. J Bone Joint Surg [Am] 1969;51:737-55.

20. Tükenmez M, Çekin T, Perçin S, Tezeren G. Internal fixation in the femoral neck fractures. C. Ü. Tıp Fakültesi Dergisi 2004;26:131-5.

21. Kaplan T, Akesen B, Demirağ B, Bilgen S, Durak K. Comparative results of percutaneous cannulated screws, dynamic compression type plate and screw for the treatment of femoral neck fractures. Ulus Travma Acil Cerrahi Derg 2012;18:65-70.

22. Atik OŞ. Which articles do we prefer to publish? Eklem Hastalik Cerrahisi 2018;29:1.

23. Levi N. Dynamic hip screw versus 3 parallel screws in the treatment of garden $1+2$ and garden $3+4$ cervical hip fractures. Panminerva Med 1999;41:233-7.

24. Parker MJ, Blundell C. Choice of implant for internal fixation of femoral neck fractures. Meta-analysis of 25 randomised trials including 4,925 patients. Acta Orthop Scand 1998;69:138-43.

25. Jain R, Koo M, Kreder HJ, Schemitsch EH, Davey JR, Mahomed NN. Comparison of early and delayed fixation of subcapital hip fractures in patients sixty years of age or less. J Bone Joint Surg [Am] 2002;84:1605-12.

26. Upadhyay A, Jain P, Mishra P, Maini L, Gautum VK, Dhaon BK. Delayed internal fixation of fractures of the neck of the femur in young adults. A prospective, randomised study comparing closed and open reduction. J Bone Joint Surg [Br] 2004;86:1035-40.

27. Singh M, Sonkar D, Verma R, Shukla J, Gaur S. Comparison of the functional outcome of DHS versus cannulated cancellous screws in pauwels type II and III fracture neck femur in young adults. International Journal of Orthopaedics Sciences 2017;3:745-9.

28. Zlowodzki M, Brink O, Switzer J, Wingerter S, Woodall $\mathrm{J}$ Jr, Petrisor BA, et al. The effect of shortening and varus collapse of the femoral neck on function after fixation of intracapsular fracture of the hip: a multi-centre cohort study. J Bone Joint Surg [Br] 2008;90:1487-94.

29. Mattsson P, Alberts A, Dahlberg G, Sohlman M, Hyldahl HC, Larsson S. Resorbable cement for the augmentation of internally-fixed unstable trochanteric fractures. A prospective, randomised multicentre study. J Bone Joint Surg [Br] 2005;87:1203-9. 